\title{
Vascularized pedicle iliac bone grafts as a hip-preserving surgery for femur head necrosis: a systematic review
}

\author{
Fan Yang ${ }^{1 \dagger}$, Qiushi Wei $^{2+}$, Xiaojun Chen ${ }^{1}$, Guoju Hong ${ }^{1}$, Zhenqiu Chen ${ }^{2}$, Yaolong Chen ${ }^{3}$ and Wei He ${ }^{2 *}$ (D)
}

\begin{abstract}
Background: Osteonecrosis of the femoral head was gradually concerned as a global disease for its progression to collapse of the femoral head, ultimately causing the arthritic change. Due to the high incidence of this disease in young people, arthroplasty tends to be suspected for its uncertain long-term efficiency. Vascularized pedicle iliac bone grafts, as a hip-preserving surgery, were regarded as an effective option in hip-preserving protocol since the 1970s. Nevertheless, there exist no unified standards widely agreed as the optimal operative program since the lack and heterogeneity of related studies. Thus, we execute this systematic review to synthesize and analyze existing studies, and further suggest a direction of future researches.

Methods: Data were collected by searching electronic database (PubMed, Embase, and Cochrane Library) and including the eligible studies of all types of clinical researches except case report. Through our extraction and synthesis of included study results in respect of clinical evaluation (rating scales), radiographic evaluation, joint survival rate, viability of implanted flap, and complications by transform varied assessment method into a unified standard, we qualitatively analyze and discuss the efficacy of VPIBG according to the quality of individual study and the heterogeneity across the included studies.
\end{abstract}

Results: Our systematic review includes 1 RCT, 2 case-control studies, and 13 case series studies, resulting in a significant improvement of postoperative scores. Minority of hips progressed for joint replacement. Some researches suggested a high collapse rate in the collapsed femoral head before the operation. Compared with some other hip-preserving surgeries, the complications of VPIBG are relatively slight and barely affect clinical efficiency.

Conclusions: A better clinic response was obtained after this treatment, especially in femoral heads before the appearance of a crescent sign. The fixation of the implanted iliac bone flap increases the clinical effect. The majority of complications were slight and rarely affected clinical efficacy.

Keywords: Osteonecrosis, Femoral head, Bone grafts, Vascularized pedicle ilium, Systematic review

\section{Introduction}

Osteonecrosis of the femoral head (ONFH) has been gradually treated as a devastating disease and become an increasing worldwide health problem. Evidences have indicated a nonnegligible morbidity in the USA [1-3], Japan [4], and Korea [5]. The main pathomechanism generally accepted involves a reduction in the blood

\footnotetext{
* Correspondence: hw13802516062@163.com

${ }^{\dagger}$ Fan Yang and Qiushi Wei contributed equally to this work.

${ }^{2}$ Institute of Hip Joint, First Affiliated Hospital of Guangzhou University of

Chinese Medicine, Guangzhou, Guangdong, China

Full list of author information is available at the end of the article
}

supply to the femoral head caused by high-dose corticosteroid use [6], alcohol abuse [7], fracture of the femoral head $[7,8]$, chemotherapy regimens [9], and other unknown etiological that were considered as idiopathic necrosis [10]. For the reason of its pathogenesis is poorly understood and the absence of specific treatment, most cases ultimately progress to femoral head collapse and joint destruction, with hip arthroplasty being the appropriate treatment option [11]. Due to the young age of the patients $[4,5]$ and uncertainty of long-term survivorship of prosthesis [12], however, concerns regarding the

(C) The Author(s). 2019 Open Access This article is distributed under the terms of the Creative Commons Attribution 4.0 International License (http://creativecommons.org/licenses/by/4.0/), which permits unrestricted use, distribution, and 
complexity of revision surgery have been gradually highlighted. Thus, there is great interest in procedures, for instance, the joint-preserving surgeries, which could slow disease progression [13].

Vascularized pedicle iliac bone grafting (VPIBG), as a widely used joint-preserving surgery since the 1970s [14], could reduce pressure of the femoral head, diminish intraosseous pressure, provide structural support, and restore vascular supply to enhance lesion healing, therefore enhancing the stability of femoral head structure and preventing collapse or secondary collapse. The deep iliac circumflex artery (DICA), superficial iliac circumflex artery (SICA), and ascending branch of the lateral circumflex artery (ALCA) are generally used as nutrient vessels for the iliac bone flap. Vascularized muscle-pedicle bone flap was also considered to be a kind of vascularized pedicle iliac bone flap.

According to the existing literature which could be retrieved from database on the Internet, there have been no review articles to assess the efficacy of VPIBG as a treatment protocol for ONFH. Thus, we performed this systematic review for two purposes: (1) to investigate the clinical and radiographic results of different kinds of VPIBG and (2) to compare the effectiveness of VPIBG influenced by the initial radiographic stage and time of follow-up (Fig. 1).

\section{Methods}

Our systematic review of the literature adhered to the PRISMA guidelines [15, 16]. Methods of the analysis and inclusion criteria were specified in advance.

\section{Eligibility criteria}

Types of studies

All types of clinical trials except case report were included in this systematic review. And the language was limited to English.

\section{Types of participants}

Participants included are those diagnosed with ONFH, who were not performed surgeries on the involved hip except the fixation of femoral neck fracture in traumatic femoral head necrosis. Studies including the majority of juveniles were excluded.

\section{Types of intervention}

Studies that executed VPIBG were included. If studies examined other treatments, which have been proved to be effective, they will be excluded.

\section{Types of outcome measures}

The outcome of included trials should contain at least three kinds of measurements: clinical measurements (Harris scores, JOA scores, etc.), radiography measurements, or survival rate of the involved hips.

\section{Search strategy}

Studies were identified by searching electronic databases and scanning reference lists of articles. This search was applied to PubMed, Embase, and the Cochrane Library using the following key terms: femur head necrosis, iliac bone grafting, bone grafting, etc. (Additional file 1: Appendix 1). The last search was run on 13 July 2016.

\section{Study selection}

Two reviewers independently assessed the titles and abstracts of the articles retrieved. For all potentially eligible articles, the full text was obtained and evaluated against the eligibility criteria. Any disagreement between reviewers was resolved by discussion.

\section{Data collection and analysis}

Data extraction included study design, population (patients/hips), and the like by using standardized forms. The VPIBG operation protocols of each study were carefully recorded. The outcome of interest includes clinical evaluation (Harris score, JOA score, etc.), radiographic evaluation (radiographic failure rate), hip survival rate, viability evaluation, and complications. As a result of the different use of scales for clinical evaluation, we analyzed Harris score and other scales respectively, and Harris score was assessed by transforming it into mean

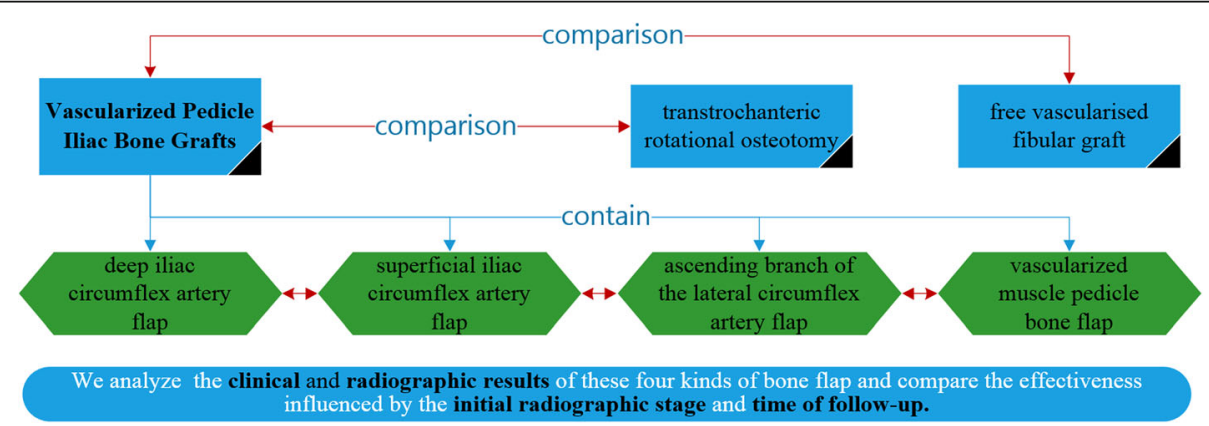

Fig. 1 The roadmap of the qualitative analysis 
difference between pre-operation and last follow-up. In addition, clinical success was defined as Harris score $\geq$ 80 (Merle d'Aubigne and Postel score $\geq 15$, Charnley hip score $\geq 15$, HSS $\geq 24$ ); then, clinical success rate could be calculated.

For radiographic evaluation, the kinds of classification system [17] used in studies were converted in accordance with Ficat classification system if possible, for the reason of their similar fundament Table 1. Based on this method, radiographic failure was defined as any lesions progressed to a higher stage from baseline stage except stage I progressed to stage II. And the need for arthroplasty was classified into radiographic failure. Then, the radiographic failure rate was calculated. We collected the date of conversion to arthroplasty or hips requiring secondary operative intervention. Then, the rate of convention to arthroplasty was calculated.

For the reason of different follow-up time of these included studies, we categorized the duration of follow-up to short term (less than 6 years) and long term (more than 6 years) because most patients would perform hip replacement surgery in 6 years if the results of VPIBG were not good.

Meta-analysis could not be conducted due to the methodological heterogeneity and the limited number of the available controlled studies. Therefore, we only qualitatively analyze the results extracted from the included studies.

\section{Risk of bias in individual studies}

The methodological study quality was assessed using a checklist for the quality appraisal of case series studies that was developed at the Institute of Health Economics (IHE) [18]. The checklist consisted of 20 criteria. Each study was reviewed by answering "yes," "partial," "no," or "unclear." "Partial" responses were considered "yes," and "unclear" was considered "no"; then, we calculate the number of "no" for estimating the risk of bias. A study with 0-2 "no" responses was considered to have a low risk of bias, 3-5 "no" responses a moderate risk, $6-8$ a high risk, and $\geq 9$ a very high risk of bias [19]. For randomized controlled trial, the Cochrane risk of bias tool was used [20]. The level of evidence of each study was rated on the basis of the Oxford Centre for Evidence-based Medicine-Levels of Evidence (March 2009) (Additional file 1: Appendix 2).

\section{Results}

\section{Study selection}

A total of 16 studies were identified for inclusion in the review. No eligible studies were found by checking the references of location. The detailed process was shown in the flow diagram (Fig. 2).

\section{Study characteristics}

The clinical studies included one randomized control trial (RCT) [21], two case-control studies [22, 23], and 13 case series studies [24-36]. The length of follow-up for the RCTs was 12 months. The two case-control studies had a follow-up that ranged from 3 to 16 years. And the remaining case series were followed up for 2.87 to 16.50 years. The validity of the studies is summarized in Tables 2 and 3 and Additional file 1: Appendix 3.

The included studies comprised of 877 participants (1011 hips). The main inclusion criteria entailed adults (mean age varied from 30 to 40), who suffered from the following etiology: trauma, steroid use, alcohol abuse, idiopathic, etc.

The severity of AVN was classified using diverse grading systems. Seven of these studies [21, 24-26, 28, 30, 31] utilized the Association Research Circulation Osseous (ARCO) classification. Five studies [23, 27, 29, 32, 34] used the Ficat classification. And the others used Steinberg, JIC, Inoue and Ono classification, Myer's

Table 1 The relationship between stage classifications system of ONFH

\begin{tabular}{|c|c|c|c|c|c|c|c|c|c|c|}
\hline Ficat and alert & & I & \multicolumn{3}{|c|}{ II } & \multicolumn{3}{|c|}{ III } & \multirow[b]{2}{*}{$\begin{array}{c}\text { IIIC } \\
\text { collapse }> \\
4 \mathrm{~mm}\end{array}$} & IV \\
\hline ARCO & & $\mathrm{I}$ & IIA & IIB & IIC & $\begin{array}{r}\text { III } \\
\text { cresc } \\
\text { sign, collap }\end{array}$ & $\mathrm{e}<2 \mathrm{~mm}$ & $\begin{array}{c}\text { IIIB } \\
2<\text { collapse } \\
<4 \mathrm{~mm}\end{array}$ & & IV \\
\hline Steinberg & 0 & I & \multicolumn{3}{|c|}{ II } & III & \multicolumn{3}{|c|}{ IV } & V,VI \\
\hline Myer's classification & & & & & & $\begin{array}{c}\text { III } \\
\text { crescent } \\
\text { sign, no } \\
\text { collapse }\end{array}$ & \begin{tabular}{|c|} 
IV \\
collapse $<2$ \\
$\mathrm{~mm}$
\end{tabular} & \multicolumn{2}{|c|}{$\begin{array}{c}\mathrm{V} \\
\text { collapse }>2 \mathrm{~mm}\end{array}$} & \\
\hline JIC stage & & $\mathrm{I}$ & \multicolumn{5}{|c|}{ II } & \multicolumn{2}{|c|}{ III } & IV \\
\hline Inoue and Ono classification & & I & \multicolumn{5}{|c|}{ The density in femoral head has changed } & \multicolumn{2}{|c|}{ III } & IV \\
\hline $\begin{array}{l}\text { Marcus, Enneking and } \\
\text { Massam stage }\end{array}$ & & & $\begin{array}{c}\text { I } \\
\text { The density in } \\
\text { femoral head } \\
\text { has changed }\end{array}$ & \multicolumn{2}{|c|}{$\begin{array}{c}\text { II } \\
\text { The density of } \\
\text { necrotic area is } \\
\text { high }\end{array}$} & $\begin{array}{c}\text { III } \\
\text { crescent sign }\end{array}$ & $\begin{array}{c}\text { IV } \\
\text { Lateral } \\
\text { collapse }\end{array}$ & \multicolumn{2}{|c|}{$\begin{array}{c}\text { V } \\
\text { collapse in necrotic } \\
\text { area }\end{array}$} & $\begin{array}{c}\text { VI } \\
\text { osteoarthritis } \\
\text { change }\end{array}$ \\
\hline
\end{tabular}




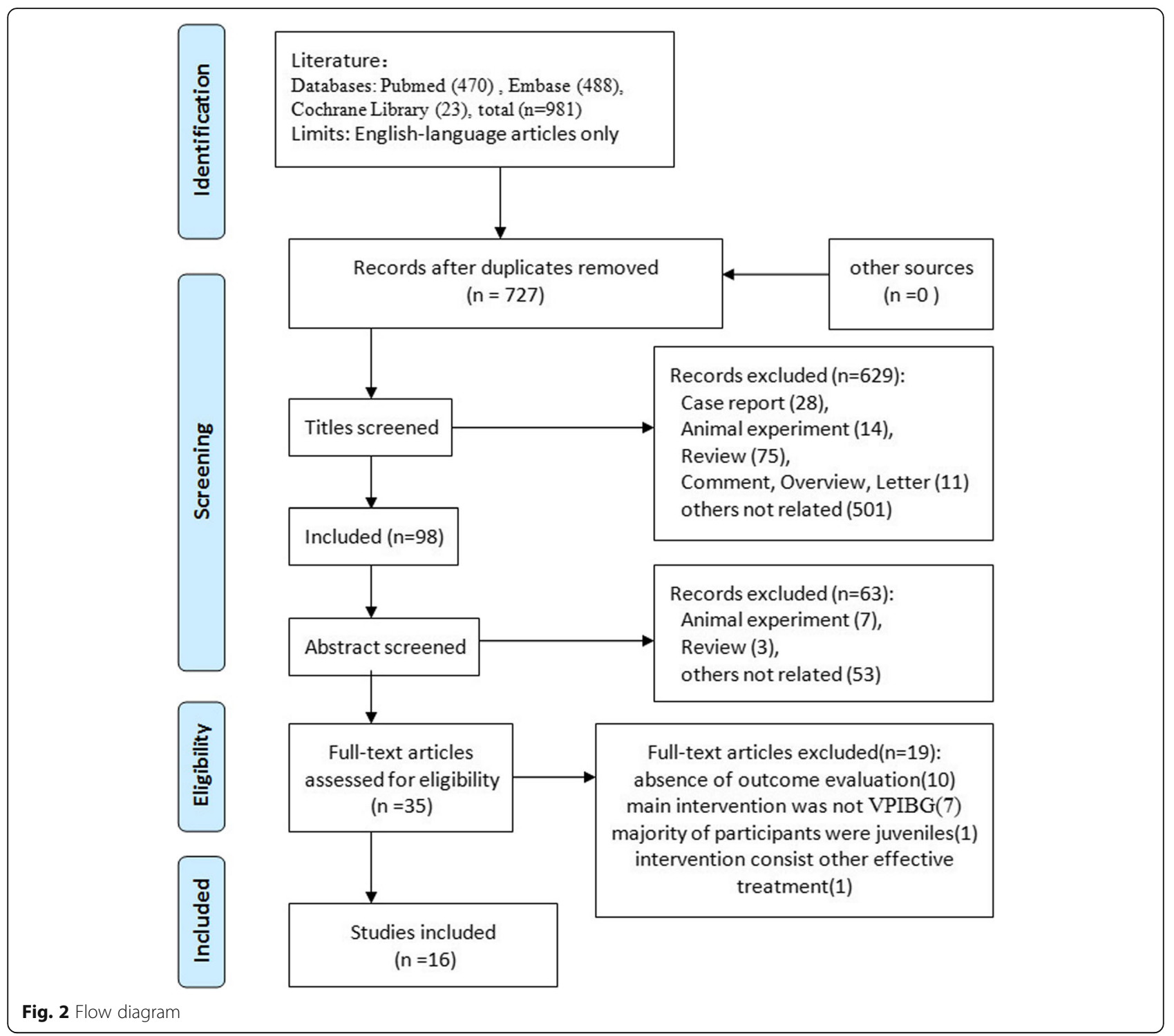

classification, respectively (Table 2). And Table 1 summarizes the relationship between these classifications based on their similar fundament.

Five studies [22, 23, 27, 33, 36] described the indications of VPIBG. Majority of the indications reported share the same concept, and we synthesized into the following items: (1) pain and discomfort around the hip and the limitation of movement of the hip [27], (2) collapse of femoral head was less than $2 \mathrm{~mm}[33,36]$, (3) IC or II class femoral head according to JIC classification $[23,33]$, and (4) femoral heads collapsing more than 5 $\mathrm{mm}$ were not recommended to perform VPIBG [36]. Femoral heads classified into ARCO IIIB or IIIC stage were also considered as the indications in 2 studies [22, 23].

The nutrient vessels for iliac bone flap used by included studies cover DICA [23, 25, 26, 28, 30-33, 35,
36], SICA [23, 33, 36], and ALCA [21, 29]. Two studies $[24,27]$ used tensor fascia lata and sartorius muscle-pedicle bone flap respectively. And the kind of flap used was not mentioned in the remaining 2 studies $[22,34]$ (Tables 4 and 5).

As to the average time of operation, sartorius musclepedicle bone flap grafting costs the shortest [24], for only 45 to $90 \mathrm{~min}$. DICA bone grafting takes 2.8 to $4.3 \mathrm{~h}$ [25, 32], and ALCA bone grafting 0.92 to $2 \mathrm{~h}$ [29]. Several studies additionally fixed grafted flap by biodegradable Mg screw [21], absorbable screws [24], AO screws [30], and Vicryl thread [27].

\section{Outcome}

Across the included trials, the outcome was measured by various methods including clinical evaluation, radiographic evaluation, hip survival rate, and complications 


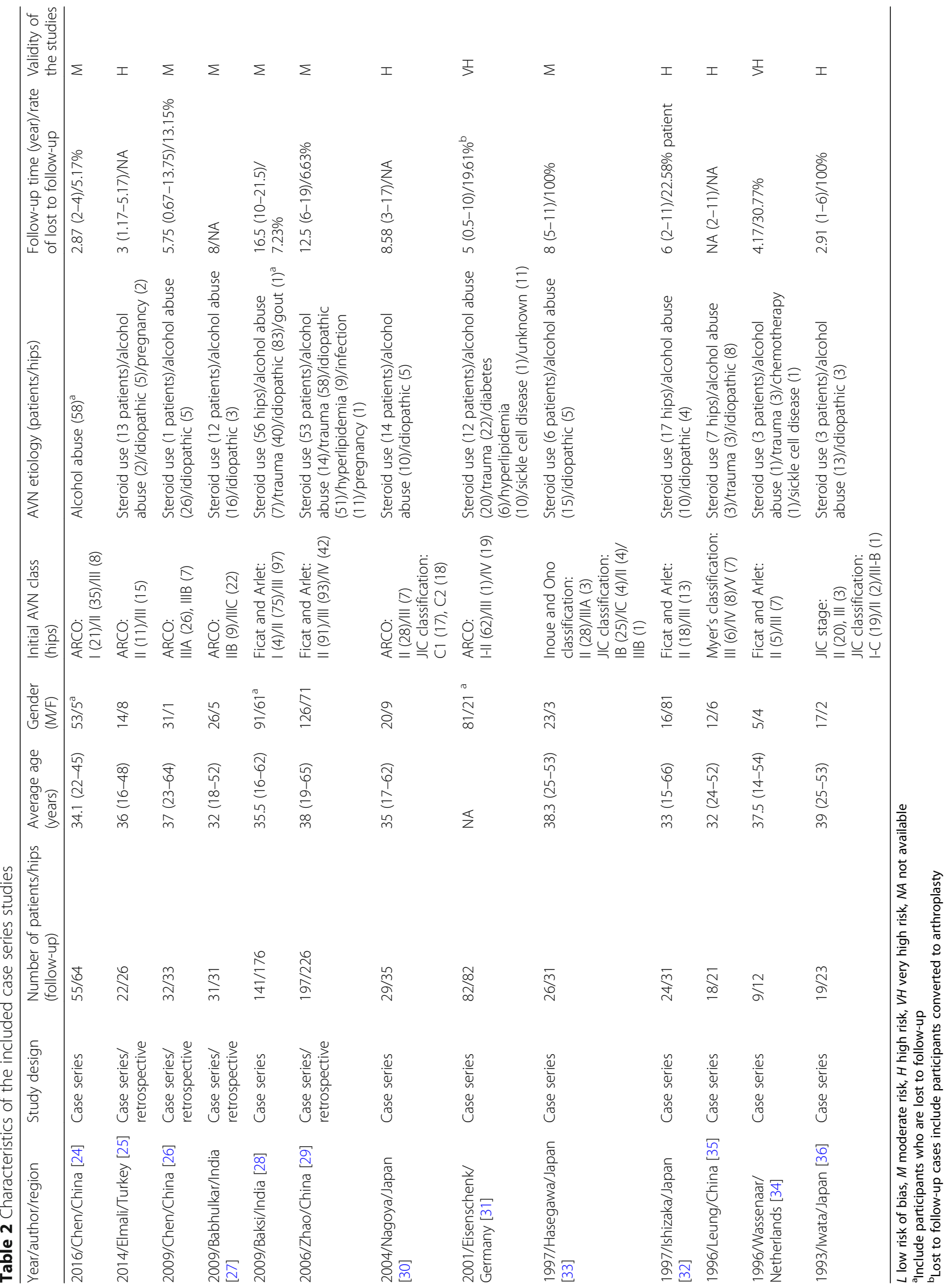




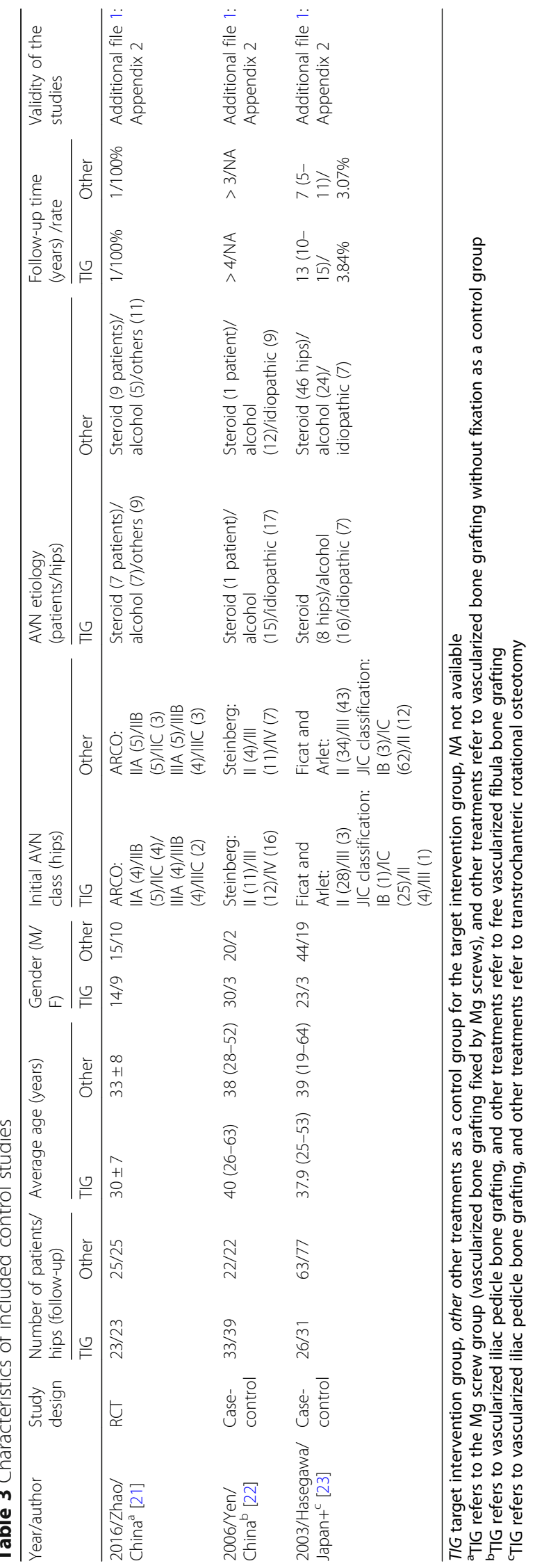




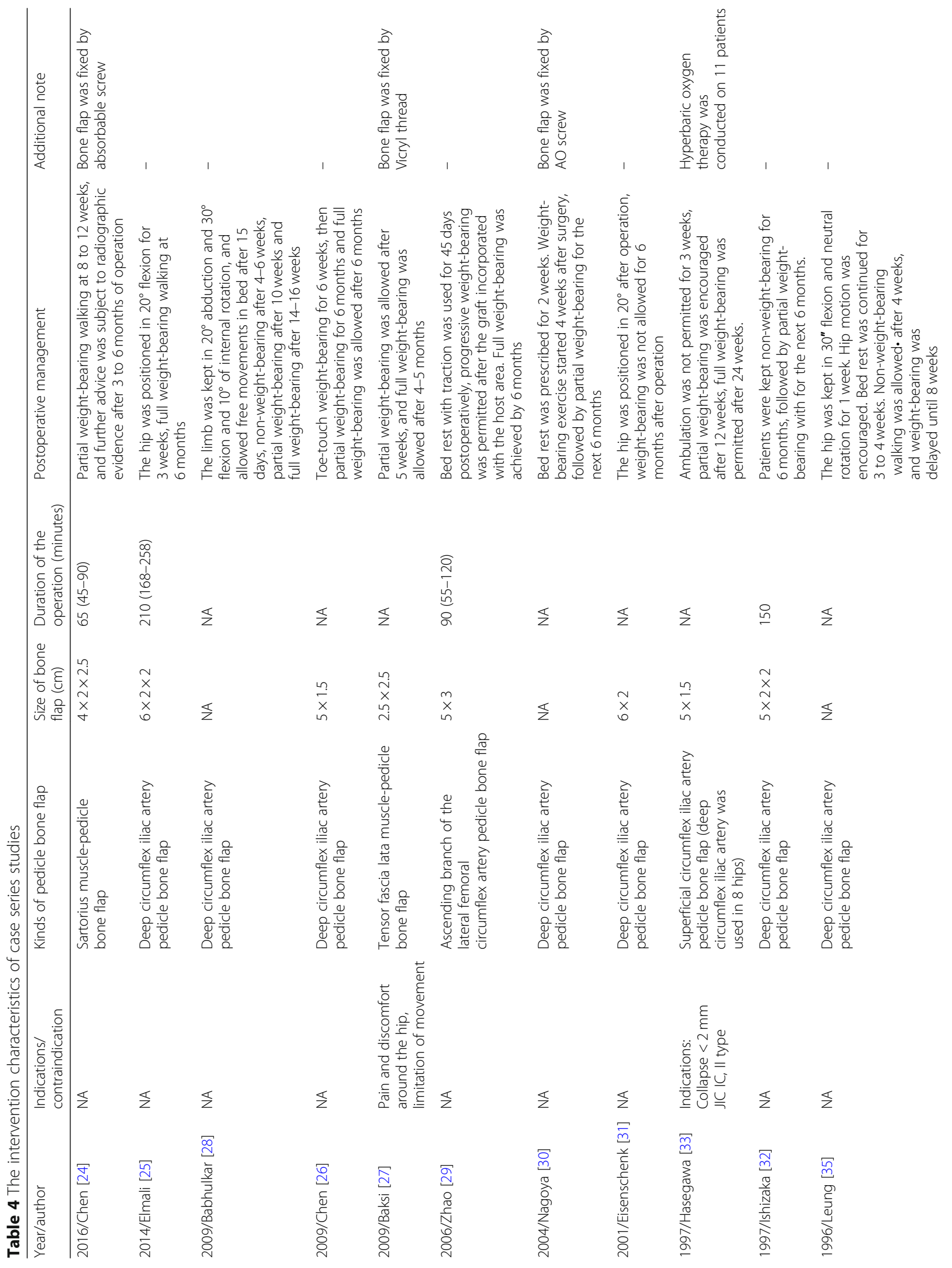




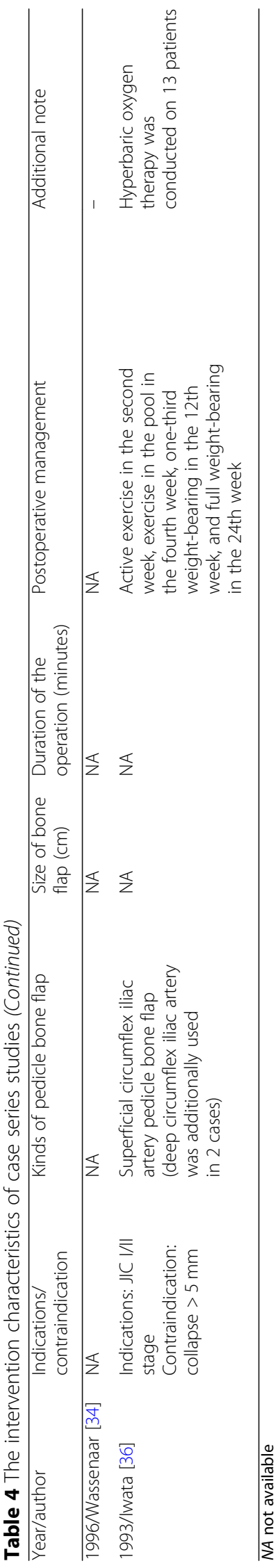


Table 5 The intervention characteristics of the control studies

\begin{tabular}{|c|c|c|c|c|c|c|c|c|c|c|c|}
\hline \multirow[t]{2}{*}{ Year/author } & \multirow[t]{2}{*}{$\begin{array}{l}\text { Indications/ } \\
\text { contraindication }\end{array}$} & \multicolumn{2}{|l|}{$\begin{array}{l}\text { Kinds of pedicle } \\
\text { bone flap }\end{array}$} & \multicolumn{2}{|c|}{$\begin{array}{l}\text { Size of } \\
\text { bone flap }(\mathrm{cm})\end{array}$} & \multicolumn{2}{|c|}{$\begin{array}{l}\text { Duration of the } \\
\text { operation } \\
\text { (minutes) }\end{array}$} & \multicolumn{2}{|c|}{$\begin{array}{l}\text { Postoperative } \\
\text { management }\end{array}$} & \multicolumn{2}{|l|}{$\begin{array}{l}\text { Additional } \\
\text { note }\end{array}$} \\
\hline & & $\overline{T I G}$ & Other & $\overline{\mathrm{TIG}}$ & Other & $\overline{\mathrm{TIG}}$ & Other & $\overline{T I G}$ & Other & $\overline{\mathrm{TIG}}$ & Othe \\
\hline 2016/Zhao a [21] & NA & $\begin{array}{l}\text { Ascending branch of } \\
\text { the lateral femoral } \\
\text { circumflex artery } \\
\text { pedicle bone flap }\end{array}$ & & $5 \times 3$ & $5 \times 3$ & NA & NA & NA & NA & $\begin{array}{l}\text { Bone flap was } \\
\text { fixed by } \\
\text { absorbable screw }\end{array}$ & - \\
\hline $2006 / Y_{e n}{ }^{b}[22]$ & $\begin{array}{l}\text { Steinberg II, III, IV } \\
\text { Stage }\end{array}$ & NA & NA & NA & NA & 210 & 420 & NA & NA & - & - \\
\hline $\begin{array}{l}\text { 2003/Hasegawa } \\
\text { [23] }\end{array}$ & $\begin{array}{l}\text { TIG: Ficat II stage and } \\
\text { JIC IC or II type } \\
\text { Other: Ficat III stage } \\
\text { or above, and JIC IC } \\
\text { or II type, and the } \\
\text { necrosis area }<36 \% \\
\text { in frog lateral view }\end{array}$ & $\begin{array}{l}\text { Superficial circumflex } \\
\text { iliac artery pedicle } \\
\text { bone flap }\end{array}$ & - & NA & - & NA & NA & $\begin{array}{l}\text { Exerc } \\
\text { starte } \\
\text { third } \\
\text { the o } \\
\text { At } 12 \\
\text { weig } \\
(10 \mathrm{~kg} \\
24 \mathrm{we} \\
\text { weig } \\
\text { were }\end{array}$ & $\begin{array}{l}\text { were } \\
\text { the } \\
\text { k after } \\
\text { ation. } \\
\text { eks partial } \\
\text { earing } \\
\text { d at } \\
\text { full } \\
\text { earing } \\
\text { wed. }\end{array}$ & - & - \\
\hline
\end{tabular}

TIG target intervention group, other other treatments as a control group for target intervention group, NA not available

${ }^{\mathrm{a}} \mathrm{TIG}$ refers to the Mg screw group (vascularized bone grafting fixed by Mg screws), and other treatments refer to vascularized bone grafting without fixation as a control group

${ }^{\mathrm{b}} \mathrm{TIG}$ refers to vascularized iliac pedicle bone grafting, and other treatments refers to free vascularized fibula bone grafting

${ }^{\mathrm{C}} \mathrm{TIG}$ refers to vascularized iliac pedicle bone grafting, and other treatments refer to transtrochanteric rotational osteotomy

(Tables 6, 7, and 8). We summarized and analyzed the outcomes not mentioned in the table on the basis of different kinds of VPIBG respectively.

\section{Clinical evaluation}

Clinical evaluation was described using the following methods: Harris hip score [24-26, 28, 29, 31, 33, 34], Japan Orthopaedic Association hip score (JOA score) [30, 36, 37], hip rating system of the Hospital for Special Surgery (HSS score) [27], Merle d'Aubigne and Postel score (MP score), and Charnley hip scoring system (Charnley score) [22, 35]. Mean difference and clinical success rate were calculated then summarized in Tables 6 and 7.

\section{DICA pedicle iliac bone grafting}

As is shown in Tables 4 and 5, most studies used this surgical method relatively got satisfactory therapeutic results. However, Babhulkar [28] reported that only 13 (56.25\%) stage III hips got a clinical success result. Chen et al. [26] reported that the average Harris score in the last follow-up was only 64.85 in stage III hips. These 2 studies both indicated a poor result in stage III hips. But Leung's studies [35] suggested a satisfying result for a clinical success rate of $77.78 \%$ in stage III hips. Therefore, the efficiency of this surgical method between different stage hips needs further research. Ishizaka et al. [32] found the therapeutic effect was related to the position of the necrotic area, for the reason of a higher clinical success rate $(85 \%)$ in medial necrotic hips than lateral necrosis which only got a clinical success rate of
72\%. Eisenschenk et al. [31] compared the therapeutic effect in different follow-up time and indicate a better clinical result in the early outcome.

\section{SICA pedicle iliac bone grafting}

Hasegawa et al. [33] used this surgical procedure resulting in a medium clinical success rate $(63.33 \%)$. This research group previously compared the outcome in different follow-up time and primary stage of ONFH in 1993. And the results have no difference in the shortterm follow-up. Furthermore, the JOA score of the hips in early stage got a greater promotion. In 2003, a controlled study [23] was performed by them and suggested a higher clinical success rate in the TRO group than in the VPIBG group, and the clinical success rate decreased with an increase in follow-up time.

\section{ALCA pedicle iliac bone grafting}

Zhao et al. [29] executed this surgical method, and the clinical data was calculated and resulted in a poor result in stage IV hips. Furthermore, this research group performed the first randomized control trial (RCT) [21], which did a comparison of outcomes between two groups performing this surgery with or without flap fixation using biodegradable $\mathrm{Mg}$ screw. The Harris hip score exhibited a mild increase of clinical function at 12 months compared with that at 6 months after the operation. As to the clinical success rate, stage II hips exhibited a better result than stage III, especially the control group. 
Table 6 The outcome of case series studies

\begin{tabular}{|c|c|c|c|c|c|c|c|c|}
\hline \multirow[t]{2}{*}{ Year/author } & \multicolumn{2}{|l|}{ Clinical evaluation } & \multicolumn{4}{|c|}{$\begin{array}{l}\text { Clinical evaluation based } \\
\text { on the Ficat stage } \\
\text { classification } \\
\text { (mean difference/clinical } \\
\text { success rate) }\end{array}$} & \multirow[t]{2}{*}{$\begin{array}{l}\text { Radiographic } \\
\text { evaluation } \\
\text { (radiographic } \\
\text { failure rate) }\end{array}$} & \multirow[t]{2}{*}{$\begin{array}{l}\text { Complications/ } \\
\text { rate of complications }\end{array}$} \\
\hline & $\begin{array}{l}\text { Mean difference }{ }^{a} \text { (scale } \\
\text { used) }\end{array}$ & $\begin{array}{l}\text { Clinical success } \\
\text { rate } \mathrm{e}^{\mathrm{b}}\end{array}$ & I & $\|$ & III & IV & & \\
\hline 2016/Chen [24] & $31.06(\mathrm{HHS})$ & $79.68 \%$ & $\begin{array}{l}32.22 / \\
90.47 \%\end{array}$ & $\begin{array}{l}31.2 / \\
77.14 \%\end{array}$ & $\begin{array}{l}26.13 / \\
62.50 \%\end{array}$ & - & NA & NA \\
\hline 2014/EImali [25] & 30.8 (HHS) & $69.23 \%$ & - & NA & NA & - & $\begin{array}{l}34.62 \% \\
\text { II (36.36\%) } \\
\text { III (33.33\%) }\end{array}$ & $\begin{array}{l}2 \text { patients suffering from } \\
\text { obesity with serious } \\
\text { drainage for } 1 \text { week } \\
2 / 22(9.09 \%)\end{array}$ \\
\hline 2009/Babhulkar [28] & $28.19(\mathrm{HHS})$ & $58.06 \%$ & - & $\begin{array}{l}29.88 / \\
62.50 \%\end{array}$ & $\begin{array}{l}27.61 / \\
56.5 \%\end{array}$ & - & $6.45 \%$ & $\begin{array}{l}\text { Superficial infection at the } \\
\text { operative site ( } 1 \text { patient) } \\
3.22 \%\end{array}$ \\
\hline 2009/Chen [26] & $8.92(\mathrm{HHS})$ & NA & - & - & NA & - & $100 \%$ & NA \\
\hline 2009/Baksi [27] & 4.06 (HSS) & $85.79 \%$ & $1 / 100 \%$ & $4.8 / 92 \%$ & $\begin{array}{l}3.6 / \\
80.4 \%\end{array}$ & - & $9.65 \%$ & $\begin{array}{l}\text { Superficial wound infection } \\
\text { ( } 9 \text { hips), terminal limitation } \\
\text { of hip movements (20), } \\
\text { persistence of painless } \\
\text { limp (16) } \\
25.57 \%\end{array}$ \\
\hline 2006/Zhao [29] & 38 (HHS) & $86.28 \%$ & - & NA/96\% & $\begin{array}{l}\text { NA/ } \\
90 \%\end{array}$ & $\begin{array}{l}\text { NA } \\
57 \%\end{array}$ & $28.76 \%$ & $\begin{array}{l}\text { Deep venous thromboses } \\
\text { ( } 4 \text { patients), meralgia } \\
\text { paresthetica (3), secondary } \\
\text { wound healing (9) } \\
8.12 \%\end{array}$ \\
\hline 2004/Nagoya [30] & $17.35(\mathrm{JOA})$ & NA & - & NA & NA & - & NA & $\begin{array}{l}\text { Damage of cutaneus femoris } \\
\text { lateralis nerve ( } 10 \text { patients) } \\
34.48 \%\end{array}$ \\
\hline 2001/Eisenschenk [31] & NA (HHS) & $86.6 \%$ & NA & NA & NA & - & $48.89 \%$ & $\begin{array}{l}\text { Deep thrombosis of the } \\
\text { femoral vein ( } 2 \text { patients), } \\
\text { damage of cutaneus } \\
\text { femoris lateralis } \\
\text { nerve }(7) \text {, abdominal } \\
\text { weakness without evidence } \\
\text { of hernia (5), secondary } \\
\text { wound healing (2) } \\
\text { 16/82 (19.51\%) }\end{array}$ \\
\hline 1997/Hasegawa [33] & 21 (HHS) & $63.33 \%$ & - & NA & NA & - & NA & $\begin{array}{l}\text { Secondary wound healing } \\
\text { ( } 3 \text { hips), damage of } \\
\text { cutaneus femoris } \\
\text { lateralis nerve (8) } \\
36.67 \%\end{array}$ \\
\hline 1997/Ishizaka [32] & $\begin{array}{l}2.2 \text { (Merle d'Aubigne } \\
\text { and Postel score) }\end{array}$ & $77 \%$ & - & NA & NA & - & $48.38 \%$ & NA \\
\hline 1996/Leung [35] & $\begin{array}{l}5.06 \text { (Charnley hip } \\
\text { scoring system) }\end{array}$ & $77.78 \%$ & - & - & NA & - & NA & NA \\
\hline 1996/Wassenaar [34] & 28 (HHS) & NA & NA & NA & NA & - & $41.66 \%$ & NA \\
\hline 1993/Iwata [36] & $9.7(\mathrm{JOA})$ & NA & NA & 12.46/NA & $\begin{array}{l}3.34 / \\
\mathrm{NA}\end{array}$ & - & $34.78 \%$ & $\begin{array}{l}\text { Secondary wound healing } \\
\text { ( } 2 \text { hips), damage of } \\
\text { cutaneus femoris lateralis } \\
\text { nerve }(5) \\
30.43 \%\end{array}$ \\
\hline
\end{tabular}

NA not available, HHS Harris hip score, HSS Hip rating system of the Hospital for Special Surgery, JOA Japan Orthopaedic Association hip score

${ }^{a}$ The mean difference was defined as the difference between the mean score of pre-operation and final follow-up

${ }^{b}$ Clinical success was defined as the Harris score $\geq 80$ (Merle d'Aubigne and Postel score $\geq 15$, Charnley hip score $\geq 15$, HSS $\geq 24$ ) 


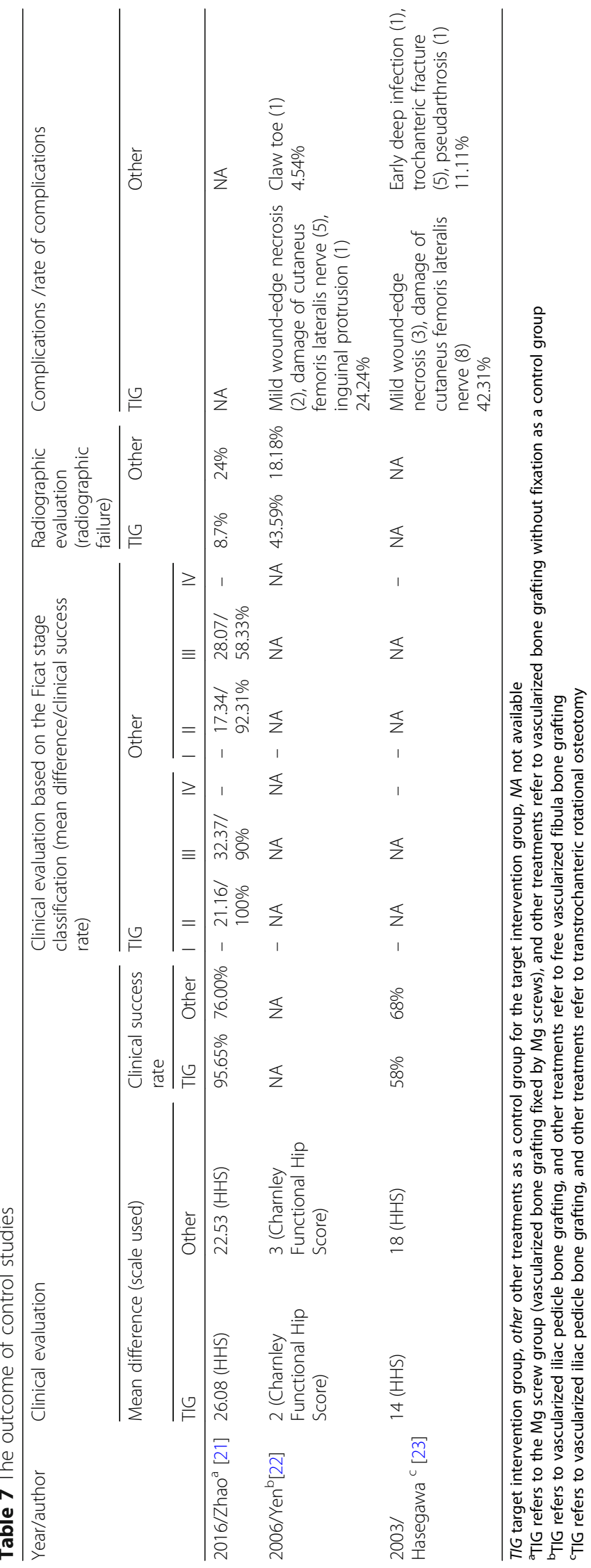


Table 8 The evaluation of hip survival

\begin{tabular}{|c|c|c|c|c|c|}
\hline Study & $\begin{array}{l}\text { Rate of convention } \\
\text { to arthroplasty } \\
\text { (arthroplasty/total hips) }\end{array}$ & $\begin{array}{l}\text { Method of report } \\
\text { in original studies }\end{array}$ & $\begin{array}{l}\text { Survival rate } \\
\text { (based on } \\
\text { the definition } \\
\text { in original studies) }\end{array}$ & $\begin{array}{l}\text { Definition of hip- } \\
\text { preservation failure } \\
\text { in individual study }\end{array}$ & $\begin{array}{l}\text { Survival rate } \\
\text { based on stage }\end{array}$ \\
\hline 2016/Zhao a [21] & $0 \%$ & NA & NA & NA & NA \\
\hline 2016/Chen [24] & $14.06 \%(9 / 64)$ & Survival curve & $81.25 \%$ & $\begin{array}{l}\text { The collapse of the femoral } \\
\text { head was larger than } \\
4 \mathrm{~mm} \text {, with significant } \\
\text { osteoarthritis; or } \\
\text { hip replacement }\end{array}$ & NA \\
\hline 2014/EImali [25] & $19.23 \%(5 / 26)$ & $\begin{array}{l}\text { Reported cases of } \\
\text { arthroplasty }\end{array}$ & NA & NA & NA \\
\hline 2009/Chen [26] & $75.76 \%(25 / 33)$ & Survival curve & $24.24 \%$ & $\begin{array}{l}\text { Conversion to replacement } \\
\text { arthroplasty }\end{array}$ & $\begin{array}{l}\text { ARCO IIIB, } 0 \% \\
\text { ARCO IIIA, } \\
30.77 \%\end{array}$ \\
\hline 2009/Babhulkar [28] & $3.23 \%(1 / 31)$ & $\begin{array}{l}\text { Reported cases of } \\
\text { arthroplasty }\end{array}$ & NA & NA & NA \\
\hline 2009/Baksi [27] & Fail to recalculate & Survival curve & $83.97 \%$ & $\begin{array}{l}\text { Radiological deterioration, } \\
\text { resulting in the reduction } \\
\text { of the clinical HSS score } \\
\text { to below 20, requiring } \\
\text { subsequent operative } \\
\text { intervention }\end{array}$ & $\begin{array}{l}\text { Ficat II, 91\% } \\
\text { Ficat III, } 82 \%\end{array}$ \\
\hline $2006 /$ Yen $^{\mathrm{b}}$ [22] & $10.26 \%(4 / 39)$ & $\begin{array}{l}\text { Reported cases of } \\
\text { arthroplasty }\end{array}$ & $10.26 \%$ & $\begin{array}{l}\text { Conversion to replacement } \\
\text { arthroplasty }\end{array}$ & $\begin{array}{l}\text { Steinberg III, } \\
75 \% \\
\text { Steinberg IV, } \\
93.75 \%\end{array}$ \\
\hline 2006/Zhao [29] & $6.19 \%(14 / 226)$ & $\begin{array}{l}\text { Reported cases of } \\
\text { arthroplasty }\end{array}$ & $93.81 \%$ & $\begin{array}{l}\text { Conversion to replacement } \\
\text { arthroplasty }\end{array}$ & NA \\
\hline 2004/Nagoya [30] & NA & NA & NA & NA & NA \\
\hline 2003/Hasegawa ${ }^{\mathrm{b}}$ [23] & $6.45 \%(2 / 31)$ & Survival curve & $\begin{array}{l}5 Y, 85 \% \\
10 Y, 67 \%\end{array}$ & $\begin{array}{l}\text { The development of } \\
\text { symptoms requiring arthroplasty } \\
\text { or a Harris hip score of } \\
\text { less than } 70 \text { points as the endpoint }\end{array}$ & NA \\
\hline 2001/Eisenschenk [31] & $8.89 \%(8 / 90)$ & $\begin{array}{l}\text { Reported cases of } \\
\text { arthroplasty }\end{array}$ & NA & NA & NA \\
\hline 1997/Hasegawa [33] & $3.23 \%(1 / 31)$ & Survival curve & $\begin{array}{l}\text { Satuation 1: } \\
3 Y, 70 \% ; 5 Y, 60 \% \\
\text { satuation 2: } \\
3 Y, 60 \% ; 5 Y, 50 \%\end{array}$ & $\begin{array}{l}\text { Satuation 1: overall clinical } \\
\text { score of less than } 70 \text { points } \\
\text { or conversion to an } \\
\text { endoprosthesis } \\
\text { satuation 2: radiographic } \\
\text { stage further than stage III-B } \\
\text { (collapse by more than } 5 \mathrm{~mm} \text { ) }\end{array}$ & NA \\
\hline 1997/Ishizaka [32] & $9.68 \%(3 / 31)$ & $\begin{array}{l}\text { Reported cases of } \\
\text { arthroplasty }\end{array}$ & NA & NA & NA \\
\hline 1996/Leung [35] & $4.76 \%(1 / 21)$ & $\begin{array}{l}\text { Reported cases of } \\
\text { arthroplasty }\end{array}$ & NA & NA & NA \\
\hline 1996/Wassenaar [34] & $8.33 \%(1 / 12)$ & $\begin{array}{l}\text { Reported cases of } \\
\text { arthroplasty }\end{array}$ & NA & NA & NA \\
\hline 1993/Iwata [36] & $4.35 \%(1 / 23)$ & $\begin{array}{l}\text { Reported cases of } \\
\text { arthroplasty }\end{array}$ & NA & NA & NA \\
\hline
\end{tabular}

NA not available

${ }^{\text {a }}$ The evaluation combined two groups

${ }^{\mathrm{b}}$ The evaluation of the VPIBG group

The two researches above both suggested better clinical results in the early stage of ONFH, but there exist marked variation in the clinical evaluation of stage III hip across two studies.

\section{Muscle-pedicle iliac bone grafting}

Baksi et al. [27] performed VPIBG using the tensor fascia lata pedicle bone flap and additionally fixed the embedded flap with Vicryl thread and observed a poorer 
result in the long-time follow-up and a better result in an early stage. A study performed by Chen et al. [24] got similar results by using the sartorius muscle-pedicle bone flap. Yen et al. [22] made a contrast between VPIBG and free vascularized fibular graft (FVFG), but did not report the type of iliac flap. And there was no obvious difference of clinical results between these two groups at the final follow-up.

\section{Radiographic evaluation}

The following methods were used for classifying the stage of ONFH: ARCO classification [21, 24-26, 28, 30, 31], Ficat and Arlet classification [23, 27, 29, 32, 34], Myer's classification [35], JIC stage classification [36], and Inoue and Ono classification [33]. According to the relation described in Table 1, these classification systems were transformed into Ficat classification if possible. The radiographic failure rate is calculated and summarized in Tables 6 and 7.

\section{DICA pedicle iliac bone grafting}

Majority of the studies resulted in a radiographic failure rate of less than 50\%. Elmali et al. [25] evaluated the radiographic result of stage II and III hips and inferred similar radiographic results across stage II and III hips. Ishizaka et al. [32] also observed no significant difference between stages II and III and reported that the necrotic hips of lateral type exhibit a higher possibility of collapse compared with those of medial type. These results coincide with the clinical evaluation. Babhulkar et al. [28] reported a low radiographic failure rate both in stage II and III hips.

In contrast, two studies reported poor radiographic results particularly in stage III hips. Chen et al. [26] reported a radiographic failure rate of $100 \%$. Nagoya et al. [30] found more stage III hip progressed to collapse more than $2 \mathrm{~mm}$ compared with stage II. And the results also indicate a better result of type C-1 hips. Furthermore, this study found that the insertion of the pedicle bone close to the anterolateral normal subchondral bone of the femoral head gave better results in terms of preventing the collapse of the femoral head.

\section{SICA pedicle iliac bone grafting}

The study performed by Iwata et al. [36] evaluates the radiographic results according to JIC classification. For the reason of small size of stage III hips, the difference of radiographic results between stage II and stage III hips has no obvious meaning. This research group evaluates a similar study performed in 1997 [33], and according to the number of stage II hips at different follow-up time reported by the two studies above, more stage II hips were observed to progress to a higher stage as time of follow-up grows, indicating a better result in short term than in long term of follow-up, which was further proved by the control study performed by the same research team in 2003 [23]. Furthermore, this controlled study also reported a higher rate of stage II hips that progressed to a higher stage in the VPIBG group compared with the transtrochanteric rotational osteotomy (TRO) group.

\section{ALCA pedicle iliac bone grafting}

Zhao et al. [29] estimated the radiographic failure rate and indicated a better result in early-stage hips. In the RCT performed in 2016 by the same research team [21], the fixation of the implanted bone flap using $\mathrm{Mg}$ screw suggested a lower radiographic failure $(8.70 \%)$ compare with the control group (24.00\%), primarily because of the low rate of flap displacement.

\section{Muscle-pedicle iliac bone grafting}

Chen et al. [24] performed VPIBG using the sartorius muscle-pedicle bone flap and Baksi et al. [27] using tensor fascia lata pedicle bone flap. Both studies suggested a better result in the early-stage hips.

Wassenaar et al. [34] and Yen et al. [22] reported no information of the iliac flap type used. The former found a higher radiographic failure rate in Ficat stage II hips (40\%) than that in stage III hips (28.57\%). Whereas this result made little sense due to the small sample size consisting only 5 stage II and 7 stage III hips, the latter compared the difference of radiographic results in the VPIBG and FVFG groups and reported a higher radiographic failure rate in the VPIBG group than in the FVFG group (43.59\% versus $18.18 \%$ ).

\section{Survival rate}

The included studies all reported the result of progression to arthroplasty or secondary surgery on involved hips after VPIBG except one study [30]. They either reported the survival rate using a Kaplan-Meier survival curve $[24,26,27,33,35]$ or the number of hips progressed to arthroplasty. Some researches defined the survival rate or failure of hip preservation in their own ways. The results are summarized in Table 8 .

As to the difference between short-term efficiency and long-term efficiency, Hasegawa et al. [33] reported the efficiency was mildly better at 3 years than 5 years of follow-up. This research team performed a longer time of follow-up in 2003 [23] and also suggested the efficacy in the short term was markedly better than that in the long term.

Baksi et al. [27] and Chen et al. [26] reported a poorer result in stage III compared with that in stage II, particularly in stage IIIB hips, of which the survival rate was $0 \%$. In contrast, the research of Yen et al. [22] 
reported a higher survival rate in Steinberg stage IV hips (equal to ARCO IIIB and IIIC) compared with that in stage III (equal to ARCO IIIA), arising a contradiction with the study of Chen et al. [26]. However, the conclusion was unrepresentative due to the small sample size.

Two included control studies [21-23] all suggest a lower rate in the FVFG and TRO group than in the VPIBG group.

\section{Viability evaluation of implanted flap}

Chen et al. [26] execute MRI or Tc-99 m single-photon emission computed tomography for viability evaluation and found the graft was viable in 24 hips (96\%). Super selective angiographies were conducted by Eisenschenk et al. [31] and indicated perfusion of the transplants in 35 patients (83.3\%). Bone grafts in the study of Wassenaar et al. [34] all demonstrated sum rounding sclerosis and fusion to the surrounding bone by radiographic evaluation. The three studies above all suggested the viability of the implanted iliac flap. On the other hand, Iwata et al. [36] found that 15 hips (65.22\%) examined by photon emission computed tomography resulted in good viability. This team confirmed this conclusion again in 1997 [33].

\section{Complications}

Ten researches [22, 23, 27-32, 36] reported complications summarized in Tables 6 and 7, which include superficial wound infection or necrosis, deep thrombosis of the femoral vein, and the like. And the occurrence rate of complications ranges from $8.12 \%$ (16/197 patients) to $42.31 \%$ (11/26 patients).

Compared with other operations such as FVFG and TRO, the complications of VPIBG has a higher occurrence rate but much slighter. Yen et al. [22] reported that one patient who accepted FVFG suffered from claw toe probably due to the wake of peroneus muscle contracture. In the study of Hasegawa et al. [23], which performed TRO to 63 patients, early deep infection occurred in one patient, trochanteric fracture in five, and pseudarthrosis in one, indicating the possibility of severe complications in some extent.

\section{Discussion}

On the basis of our retrieved result, this systematic review first summarizes and evaluates the VPIBG treatment as a hip-preserving surgery for ONFH. This protocol is suitable for the early stage of necrosis (before collapse) [38]. By opening a bone window at the junction of femoral head and neck, necrotic tissues could be excised more thoroughly than the approach via tunnels in the femoral neck [39]. Then, vascularized iliac bone flap and cancellous bone were implanted into the cavity, resulting in the mechanical support for the subchondral bone to prevent collapse. Furthermore, a favorable environment for bone induction and formation was created by the reconstruction of blood supply in the necrotic area.

Our systematic review includes case series study in 1993 and also the randomized controlled trial in recent years. Due to the large time span and national difference, the methods used to evaluate the study outcomes and severity of ONFH vary significantly. Therefore, we unify the outcome indicator based on characteristics of scales and classification system in order to compare the difference of outcome across studies. As to the analysis of results, we divided included studies into several subgroups due to the heterogeneity of their characteristics in order to recognize the difference of effectiveness influenced by the initial radiographic stage and follow-up time.

Based on the above literature survey, the effectiveness of VPIBG correlates with the stage of ONFH when the operation was conducted. Femoral heads before the collapse of subchondral bone (appearance of the crescent sign) generally get better results in clinical evaluation than those after this time point. However, there exist some differences across included studies, such as the different clinical success rate in stage III hips reported by two individual studies $[26,35]$. This may correlate with the subjectivity of the clinical evaluation or sample size. On the other hand, the radiographic evaluation also demonstrates the conclusion which the clinical results have implied. And similarly, there exist some studies that indicated no obvious difference between collapsed and pre-collapsed hips [28, 31, 32]. And these results may be affected by the short follow-up time and small sample size included by researches. In addition, studies demonstrated that surgical efficiency was related to the position of the necrotic area, for instance, the medial type of necrosis got a much better result compared with the lateral type [32], and treatment efficiency in JIC type C1 hips was better than that in type C2 hips [30]. The analysis of survival rate further approves these two conclusions above.

Some studies evaluate the clinical results at different time points of follow-up, generally suggesting a better result in the short term. Study also suggested no obvious difference on clinical efficiency within 3 to 5 years [21]. There exist two studies, however, executed by one research team in different time quantum, which demonstrated that the clinical success rate of long-term follow-up (12.5 years) preceded that of short-term follow-up (86.28\% versus $76.00 \%)$ [21, 29]. Additional examinations were executed to testify the viability of the implanted bone flap, indicating that the majority of the flaps maintained viability. Complications showed a high occurrence rate relatively, but 
the majority were slight and rarely affected clinical efficacy.

Heterogeneities exist in follow-up time, sample size, result evaluation, and interventions. Single arteriovenous pedicle provides relative abundant blood supply compared with muscles, but should be rerouted to the recipient site, and kinking, compression, or overstretching of the vascular pedicle is possible. These disadvantages ultimately result in a long operation time and high risk of failure. In contrast, the muscles contain numerous vascular communications, which were well protected within the muscle bed, to nourish the flap. And then, muscle-pedicle bone grafting procedures appear relatively easier technically. Due to the uncertainty of nourishing vessels, however, the blood supply of bone flap also remains uncertain. Some studies additionally fixed the implanted flap. In addition, the position of the flap in the femoral head also affected the results. The above mentioned all indicated that heterogeneities existing in the intervention of the included studies further lead to the heterogeneities of results.

As to the characteristics of participants in individual studies, some indicated a strong possibility of a collapse in the lateral type of necrosis compared with the medial type [32], and JIC type C-2 necrosis also resulted in a higher collapse rate compared with type C-1 [30]. However, the majority of included researches did not report the position of the necrosis area in the femoral head, which also indicated a potential heterogeneity affecting the results between studies. Besides, etiology and severity of ONFH also exist as heterogeneities leading to the heterogeneities of results across the included studies.

Compared with VPIBG, FVFG gave a lower possibility of collapse [22]. This probably associated with the stronger biomechanical support provided by fibula. The incision of a hip joint capsule in VPIBG procedure may further injure the blood supply of the femoral head. And the FVFG procedure avoids this disadvantage. Nevertheless, the incomplete excision of necrotic tissues, prolonged operation time, need of microvascular technique, donor site morbidity, and possibility of heterotopic ossification probably cause a poor efficiency and high complication rate. Femoral trochanter flap grafting was also used as a similar hip-preserving approach, generally using the transverse branch of the femoral circumflex artery as the nutrient vessels [40, 41], and the channel of bone grafting is similar to VPIBG. VPIBG combined with other approaches, such as TRO [42-44] and tantalum rod support [45], to achieve a better clinical efficiency. TRO could transfer the weight-bearing area of the femoral head to the intact area. And tantalum rod primarily reinforces the mechanical support to the subchondral bone, finally researches a similar efficacy of FVFG, and avoids the deficiency of the FVFG mentioned above.

Although we have strictly formulated uniform standards of result evaluation, our systematic review still has limitations: (1) We cannot analyze other factors like patient's comorbidities that potentially influence efficacy of VPIBG, because the included studies rarely considered this factor; (2) Due to the lack of RCT or case-control studies, the efficacy of VPIBG cannot be evaluated accurately; (3) The quality of the recommendations in this systematic review is relatively low, for the reasons of heterogeneity among the included studies. Finally, we only executed a descriptive analysis for this systematic review, instead of a quantitative analysis.

\section{Conclusion}

In combination with what has been discussed above, the VPIBG gets a better clinic response in ONFH before the appearance of a crescent sign through $\mathrm{X}$-ray graphs compared with the femoral head after the collapse. And a better result is gotten in the short term compared with a long-term follow-up, but there exists no obvious difference on clinic efficiency within 3 to 5 years. The fixation of the implanted iliac bone flap increases the clinical effect. As for the complications of VPIBG, the majority were slight and rarely affected clinical efficacy. Nevertheless, on account of the lack of high-quality research presented and inter-study heterogeneity, these conclusions need the support of further research, which includes (1) more control studies, especially RCTs, to verify the clinical utility by comparing with other treatments; (2) unified result evaluation system to reduce heterogeneity; and (3) operation approach which needs to be further standardized, in order to find out the optimization-specific protocol of VPIBG.

\section{Additional file}

Additional file 1: Appendix 1. Search strategy: PubMed. Appendix 2. Oxford Centre for Evidence-based Medicine-Levels of Evidence (March 2009). Appendix 3. Quality evaluation of included studies case series studies. (DOCX $33 \mathrm{~kb})$

\section{Abbreviations \\ ALCA: Ascending branch of the lateral circumflex artery; ARCO: Association Research Circulation Osseous; DICA: Deep iliac circumflex artery; JIC: Japanese investigation criteria; ONFH: Osteonecrosis of the femoral head; RCT: Randomized controlled trial; SICA: Superficial iliac circumflex artery; VPIBG: Vascularized pedicle iliac bone grafts}

\section{Acknowledgements}

This study was supported in part by grants from the following project: National Natural Science Foundation of China (Nos. 81473697 and 81573996), the Science and Technology Plan Project of Guangdong Province (No. 2016A020226028), Natural Science Foundation of Guangdong Province (2017A030313698), Special Construction Project of Dominant Disease (ONFH) of Chinese Medicine in Guangdong Province ([2015]19), and Inheritance Studio Construction Project of Prestigious TCM Doctors (He Wei) in 
Guangdong Province ([2017]17). The funders had no role in the study design, data collection and analysis, decision to publish, or preparation of the manuscript. The authors declare that they have no competing interests for the publication of this paper.

\section{Authors' contributions}

FY designed the study. FY and $\mathrm{QW}$ acquired the data. QW and GH analyzed the data. FY and XC wrote the manuscript. YC support the method guidance. $Y C$ and $W H$ revised the manuscript. All authors read and approved the final manuscript.

\section{Availability of data and materials}

Data sharing is not applicable to this article as no datasets were generated or analyzed during the current study.

\section{Ethics approval and consent to participate}

Not applicable.

\section{Consent for publication}

Not applicable.

\section{Competing interests}

The authors declare that they have no competing interests.

\section{Author details}

${ }^{1}$ The First Clinical Medical School, Guangzhou University of Chinese Medicine, Guangzhou 510405, Guangdong, China. ${ }^{2}$ Institute of Hip Joint, First Affiliated Hospital of Guangzhou University of Chinese Medicine, Guangzhou, Guangdong, China. ${ }^{3}$ Key Laboratory of Evidence Based Medicine of Lanzhou University, Lanzhou, Gansu, China.

Received: 19 December 2018 Accepted: 8 July 2019

Published online: 27 August 2019

\section{References}

1. Coventry MB, Beckenbaugh RD, Nolan DR, Ilstrup DM. 2,012 total hip arthroplasties. A study of postoperative course and early complications. J Bone Joint Surg Am. 1974;56(2):273-84.

2. Mankin HJ. Nontraumatic necrosis of bone (osteonecrosis). N Engl J Med. 1992:326(22):1473-9.

3. Mont MA, Hungerford DS. Non-traumatic avascular necrosis of the femora head. J Bone Joint Surg Am. 1995;77(3):459-74

4. Ikeuchi K, Hasegawa Y, Seki T, Takegami Y, Amano T, Ishiguro N. Epidemiology of nontraumatic osteonecrosis of the femoral head in Japan. Mod Rheumatol. 2015;25(2):278-81.

5. Kang JS, Park S, Song JH, Jung YY, Cho MR, Rhyu KH. Prevalence of osteonecrosis of the femoral head: a nationwide epidemiologic analysis in Korea. J Arthroplast. 2009;24(24):1178-83.

6. Klingenstein $\mathrm{G}$, Levy RN, Kornbluth A, Shah AK, Present DH. Inflammatory bowel disease related osteonecrosis: report of a large series with a review of the literature. Aliment Pharmacol Ther. 2005;21(21):243-9.

7. Tsai SW, Wu PK, Chen CF, et al. Etiologies and outcome of osteonecrosis of the femoral head: etiology and outcome study in a Taiwan population. J Chin Med Assoc. 2015;79(1):39-45.

8. Kamal D, Trăistaru R, Alexandru DO, et al. Morphometric findings in avascular necrosis of the femoral head. Romanian J Morphol Embryol. 2012; 53(3 Suppl):763-7.

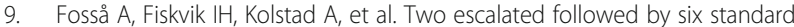
BEACOPP in advanced-stage high-risk classical Hodgkin lymphoma: high cure rates but increased risk of aseptic osteonecrosis. Ann Oncol. 2012;23(5): 1254-9.

10. Battaglia PJ, Gliedt J, Mcdaniel C, Kettner N. Bilateral idiopathic osteonecrosis of the femoral head: a case report with an emphasis on differential diagnosis, imaging, and treatment. J Chiropr Med. 2014;13(3): 196-202.

11. Mont MA, Cherian JJ, Sierra RJ, Jones LC, Lieberman JR. Nontraumatic osteonecrosis of the femoral head: where do we stand today? A ten-year update. J Bone Joint Surg Am. 2015;97(19):1604-27.

12. Warth LC, Callaghan JJ, Liu SS, Klaassen AL, Goetz DD, Johnston RC. Twentyfive-year results after Charnley total hip arthroplasty in patients less than fifty years old: a concise follow-up of a previous report. J Bone Joint Surg Am. 2014:96(21):1814-9.

13. Lieberman JR, Engstrom SM, Meneghini RM, Soohoo NF. Which factors influence preservation of the osteonecrotic femoral head? Clin Orthop Relat Res. 2012;470(2):525-34

14. Davis JB, Fagan TE, Beals RK. Follow-up notes on articles previously published in the journal. Muscle-pedicle bone graft in hip fusion. J Bone Joint Surg Am. 1971;53(8):1645-7.

15. Moher D, Liberati A, Tetzlaff J, Altman DG, PRISMA group. Preferred reporting items for systematic reviews and meta-analyses: the PRISMA statement. Int J Surg. 2010;8(5):336-41.

16. Liberati A, Altman DG, Tetzlaff J, et al. The PRISMA statement for reporting systematic reviews and meta-analyses of studies that evaluate health care interventions: explanation and elaboration. J Clin Epidemiol. 2009;62(10):e1-34.

17. Mont MA, Marulanda GA, Jones LC, et al. Systematic analysis of classification systems for osteonecrosis of the femoral head. J Bone Joint Surg Am. 2006:88(Suppl 3):16-26.

18. Guo B, Moga C, Harstall C, Schopflocher D. A principal component analysis is conducted for a case series quality appraisal checklist. J Clin Epidemiol. 2016;69:199-207.

19. Hennequin-Hoenderdos NL, Slot DE, Van der Weijden GA. The incidence of complications associated with lip and/or tongue piercings: a systematic review. Int J Dent Hyg. 2016;14(1):62-73.

20. Higgins JPT, Green S (editors). Cochrane Handbook for Systematic Reviews of Interventions Version 5.1.0 [updated March 2011]. The Cochrane Collaboration, 2011. Available from http://handbook. cochrane.org.

21. Zhao D, Huang $S$, Lu F, et al. Vascularized bone grafting fixed by biodegradable magnesium screw for treating osteonecrosis of the femoral head. Biomaterials. 2016:81:84-92.

22. Yen CY, Tu YK, Ma CH, Yu SW, Kao FC, Lee MS. Osteonecrosis of the femoral head: comparison of clinical results for vascularized iliac and fibula bone grafting. J Reconstr Microsurg. 2006;22(1):21-4.

23. Hasegawa Y, Sakano S, Iwase T, Iwasada S, Torii S, Iwata H. Pedicle bone grafting versus transtrochanteric rotational osteotomy for avascular necrosis of the femoral head. J Bone Joint Surg Br. 2003; 85(2):191-8.

24. Chen X, Tan X, Gao S, Zhang X, Li J, Liu Y. Sartorius muscle-pedicle bone graft for osteonecrosis of the femoral head. Int Orthop. 2016;40(7):1417-25.

25. Elmalı N, Ertem K, Karakaplan M, Pepele D, Dağgez C, Topgül H. Vascular pedicled iliac bone grafting is effective in patients with an early stage of femoral head avascular necrosis. Eklem Hastalik Cerrahisi. 2014:25(1):2-7.

26. Chen CC, Lin CL, Chen WC, Shih HN, Ueng SW, Lee MS. Vascularized iliac bone-grafting for osteonecrosis with segmental collapse of the femoral head. J Bone Joint Surg Am. 2009;91(10):2390-4

27. Baksi DP, Pal AK, Baksi DD. Long-term results of decompression and musclepedicle bone grafting for osteonecrosis of the femoral head. Int Orthop. 2009;33(1):41-7.

28. Babhulkar S. Osteonecrosis of femoral head: treatment by core decompression and vascular pedicle grafting. Indian J Orthop. 2009:43(1): 27-35.

29. Zhao D, Xu D, Wang W, Cui X. Iliac graft vascularization for femoral head osteonecrosis. Clin Orthop Relat Res. 2006;442:17117-9.

30. Nagoya S, Nagao M, Takada J, et al. Predictive factors for vascularized iliac bone graft for nontraumatic osteonecrosis of the femoral head. J Orthop Sci. 2004;9(6):566-70.

31. Eisenschenk A, Lautenbach M, Schwetlick G, Weber U. Treatment of femoral head necrosis with vascularized iliac crest transplants. Clin Orthop Relat Res. 2001:386:100-5.

32. Ishizaka M, Sofue M, Dohmae Y, Endo N, Takahashi HE. Vascularized iliac bone graft for avascular necrosis of the femoral head. Clin Orthop Relat Res. 1997:337:140-8.

33. Hasegawa $Y$, Iwata $H$, Torii $S$, Iwase $T$, Kawamoto $K$, Iwasada S. Vascularized pedicle bone-grafting for nontraumatic avascular necrosis of the femoral head. A 5- to 11-year follow-up. Arch Orthop Trauma Surg. 1997;116(5):251-8.

34. Wassenaar RP, Verburg H, Taconis WK, Van der Eijken JW. Avascular osteonecrosis of the femoral head treated with a vascularized iliac bone 
graft: preliminary results and follow-up with radiography and MR imaging. Radiographics. 1996;16(3):585-94.

35. Leung PC. Femoral head reconstruction and revascularization. Treatment for ischemic necrosis. Clin Orthop Relat Res. 1996;323:139-45.

36. Iwata $\mathrm{H}$, Torii S, Hasegawa $\mathrm{Y}$, et al. Indications and results of vascularized pedicle iliac bone graft in avascular necrosis of the femoral head. Clin Orthop Relat Res. 1993;295:281-8.

37. Kuribayashi M, Takahashi KA, Fujioka M, Ueshima K, Inoue S, Kubo T. Reliability and validity of the Japanese Orthopaedic Association hip score. J Orthop Sci. 2010;15(4):452-8.

38. Millikan PD, Karas V, Wellman SS. Treatment of osteonecrosis of the femoral head with vascularized bone grafting. Curr Rev Musculoskelet Med. 2015; 8(3):252-9.

39. Hong YC, Zhong HM, Lin T, Shi JB. Comparison of core decompression and conservative treatment for avascular necrosis of femoral head at early stage: a meta-analysis. Int J Clin Exp Med. 2014;8(4):5207-16.

40. Zeng YR, He S, Feng WJ, et al. Vascularised greater trochanter bone graft, combined free iliac flap and impaction bone grafting for osteonecrosis of the femoral head. Int Orthop. 2013;37(3):391-8.

41. Zhao D, Wang B, Guo L, Yang L, Tian F. Will a vascularized greater trochanter graft preserve the necrotic femoral head? Clin Orthop Relat Res 2010:468(5):1316-24.

42. Nakamura Y, Kumazawa Y, Mitsui H, Toh S, Katano H. Combined rotational osteotomy and vascularized iliac bone graft for advanced osteonecrosis of the femoral head. J Reconstr Microsurg. 2005;21(2):101-5.

43. Matsusaki H, Noguchi M, Kawakami T, Tani T. Use of vascularized pedicle iliac bone graft combined with transtrochanteric rotational osteotomy in the treatment of avascular necrosis of the femoral head. Arch Orthop Trauma Surg. 2005;125(2):95-101.

44. Fuchs B, Knothe U, Hertel R, Ganz R. Femoral osteotomy and iliac graft vascularization for femoral head osteonecrosis. Clin Orthop Relat Res. 2003; 412:84-93.

45. Zhao D, Zhang $Y$, Wang $W$, et al. Tantalum rod implantation and vascularized iliac grafting for osteonecrosis of the femoral head. Orthopedics. 2013;36(6):789-95.

\section{Publisher's Note}

Springer Nature remains neutral with regard to jurisdictional claims in published maps and institutional affiliations.

Ready to submit your research? Choose BMC and benefit from:

- fast, convenient online submission

- thorough peer review by experienced researchers in your field

- rapid publication on acceptance

- support for research data, including large and complex data types

- gold Open Access which fosters wider collaboration and increased citations

- maximum visibility for your research: over $100 \mathrm{M}$ website views per year

At $\mathrm{BMC}$, research is always in progress.

Learn more biomedcentral.com/submissions 